\title{
La trascendental omnipresencia del pasado reciente
}

\author{
María Soledad Paz-Mackay, \\ St. Francis Xavier University
}

Verónica Garibotto. Rethinking Testimonial Cinema in Postdictatorship Argentina. Beyond Memory Fatigue. Indiana University Press, 2019.

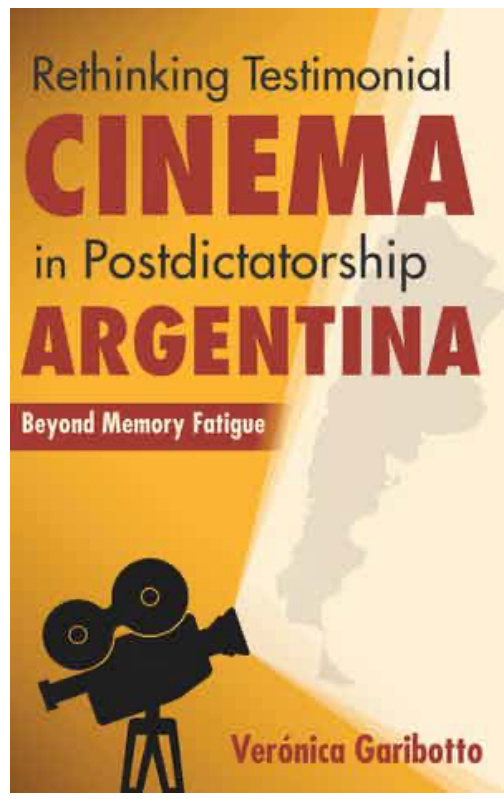

El legado de la última dictadura militar (1976-1983) y sus efectos en el presente en la sociedad argentina han sido objeto de análisis de innumerables libros escritos dentro y fuera del país, tanto en español como en inglés. De los libros publicados en Argentina en la última década, cabe mencionar dos por su gran impacto y alcance al incluir diferentes producciones culturales (cine, literatura, fotografia, teatro, rock) referidas al traumático pasado. El primero, publicado por Prometeo Libros, es el libro compilado por Fernando Reati y Margherita Cannavacciuolo, De la distancia emocional a la distancia histórica. (Re)Presentaciones del terrorismo de Estado, 40 Años después (2016). Allí, se compilan trabajos centrados en torno a las reinterpretaciones del pasado que se continúan produciendo desde el arte y el cine, con importantes análisis de colaboradores que estudian las producciones culturales de dos generaciones: la coetánea a la dictadura y la de los que eran niños durante la misma (15). El segundo libro, publicado por EUDEBA, es el editado por Jordanar Blejmar, Silvana Mandolesi y Mariana Eva Perez, El pasado Inasequible. Desaparecidos Hijos y Combatientes en el Arte y la Literatura del Nuevo Milenio (2019). El mismo reúne a una impresionante lista de expertos académicos reflexionando sobre la desaparición en hijos y combatientes de Malvinas. ${ }^{1}$ Tal como lo explican sus editoras, la "nueva estética" para referirse al traumático pasado marca el paso del tiempo, una asimilación de lo ocurrido y una perspectiva generacional que les posibilita reflexionar sobre las producciones en los años del kirchnerismo (9).

En su reciente libro Rethinking Testimonial Cinema in Postdictatorship Argentina. Beyond Memory Fatigue (2019), Verónica Garibotto propone hacer un recorrido del traumático pasado de Argentina a través del cine documental, y en particular elige centrarse en el relato testimonial erigido por la primera voz en de las últimas cuatro décadas. Así, con este libro, Garibotto decide unirse a la relevante conversación académica sobre el tema aportando una invaluable reflexión, tras sobreponerse a su sentimiento original de que era imposible decir algo nuevo sobre este creciente corpus (vii). Su objetivo central es re-examinar los acercamientos tradicionales al análisis del cine testimonial, para proponer un marco interpretativo nuevo, en la intersección de teorías del afecto y la semiótica (viii). Su intención es revisar la producción cinematográfica de Argentina producida entre 1983 y 2016. De esta forma, Gariboto se posiciona dentro de la discusión académica ya iniciada por otros intelectuales, aportando un importante estudio sobre el cine documental que va más allá de los repetidos análisis circunscriptos dentro del marco teórico del trauma o los estudios subalternos. Consecuentemente, la propuesta de Garibotto le permite, a su vez, realizar un análisis ideológico de la conexión entre cine y representación histórica. La claridad de sus ideas se refleja notablemente en la escritura a lo largo de todo el libro, lo que permite al lector adentrarse en esta

${ }^{1}$ Cabe mencionar la originalidad de esta compilación que incluye una sección dedicada a la producción cultural sobre Malvinas, titulada "Contar Malvinas”. En la misma, Jens Andermann, Patricio Pron y Victoria Torres aportan interesantes reflexiones sobre fotografía y literatura, tanto para adultos como infantil y juvenil. 
trascendente discusión acerca de la producción cinematográfica sobre el violento y tumultuoso pasado de Argentina.

En la introducción Gariboto establece con claridad los lineamientos de la robusta justificación teórica de su estudio. Luego de revisar los cambios observados en la recepción de la narrativa testimonial en torno a la dictadura, Garibotto se refiere a la reserva mostrada por varios sectores de académicos y artistas argentinos hacia el uso de la narrativa testimonial. Para ella, en lugar de descartar los excesivos textos de la memoria, es necesario reconocerlos como discursos del presente (4). Así, sus ideas parten del entendimiento y estudio del síntoma de "memory fatigue" (4); en particular por la importancia de este en el presente de Argentina. Luego, Garibotto expone el andamiaje de su acercamiento teórico en tres importantes secciones. En la primera, parte del análisis del libro de Beatriz Sarlo, Tiempo pasado, dado el alto impacto y controversia que produjo. En su opinión, la reticencia de Sarlo de aceptar el testimonio esconde el espíritu elitista de preservar el poder de los intelectuales. Luego, revisa la defensa del testimonio por académicos que se basan en las teorías subalternas y de trauma, para exponer su tesis. Su argumento gira en torno a la incapacidad de ambas teorías, por su análisis no histórico, de proporcionar válidas lecturas en la producción de posdictadura, en particular a partir de 2000. En cambio, propone redefinir el foco interpretativo en miras a explicar la reticencia hacia el género testimonial, para así rediseñar una ética intelectual acorde a la coyuntura política actual de Argentina (8). Argumenta, además, que el problema se encuentra en cómo son leídos los textos testimoniales; ya que en este nivel interpretativo "the access to history has become a problem" (9). En la segunda sección, Garibotto se ocupa de explicar los motivos por los cuales, en su opinión, los estudios subalternos y de trauma no son efectivos para el estudio del testimonio en Argentina, especialmente después del 2000. Finalmente, en la tercera sección expone en detalle los argumentos teóricos que utiliza en su análisis, y propone restaurar la historicidad ${ }^{2}$ en el análisis de los documentales, mediante la combinación de teorías del afecto y la semiótica. Antes de comenzar con el análisis específico de los filmes, Garibotto propone una redefinición del cine testimonial que incluya la idea de historicidad; y alejándose de la dualidad documental- ficción, lo entiende como aquel "enunciated by protagonist or witnesses of the military regime that rule Argentina between 1976 and 1983" (27).

En los cuatro capítulos de análisis la autora pone especial atención a la interrelación de los tres niveles de interpretación: la representación textual de la historia, la interrelación entre esta y el presente de enunciación, y su ubicación temporal dentro de a historia (16); y realiza lecturas sincrónicas y diacrónicas de la producción de documentales en 1980, 1990 y 2000, que fueron tres momentos distintivos en los discursos sobre la dictadura. Ella entiende que este análisis puede superar la fatiga que existe sobre este tema, contribuyendo a un mejor entendimiento de la narrativa testimonial de Argentina. Asimismo, basándose en conceptos de la semiótica, Garibotto sostiene que tanto las dimensiones simbólicas como icónicas son también centrales para reconstruir la historicidad en los documentales. Por último, concentrándose en las teorías de los sentimientos que permiten lecturas que recuperan la historicidad en el cine de postdictadura, sigue la distinción entre emoción (un sentimiento codificado) y afecto (sentimientos sin conceptualizar). Así, explica que "what is represented and the feelings associated with these representations are crucial to understanding what is a stake in testimonial films" (22). En el primer capítulo la autora analiza el documental Juan, como si nada bubiera ocurrido (1987) y la película La noche de los lápices (1986), con el objetivo de desmantelar las rígidas interpretaciones de estos dos; y propone una redefinición del cine testimonial que le permite incluir la idea de cómo los documentales de los primeros años del regreso a la democracia fomentaron la participación cívica, crearon nuevos afectos y ofrecieron versiones alternativas de la historia (24). En el segundo capítulo estudia tres documentales de los 90, Montoneros: una historia (1994), Cazadores de utopias (1996) y Botín de guerra (1999), y sugiere que estos toman una posición anti-oficial y contra-hegemónica (24). El foco del tercer capítulo son los muy analizados documentales Papa

\footnotetext{
2 Para Garibotto, recuperar la historicidad de los textos no solo se refiere a la representación de la historia en los mismos, sino también a que se debe considerar aquellas características que los textos adoptan como resultado de su inscripción en la historia, sincrónica y diacrónica (15).
} 


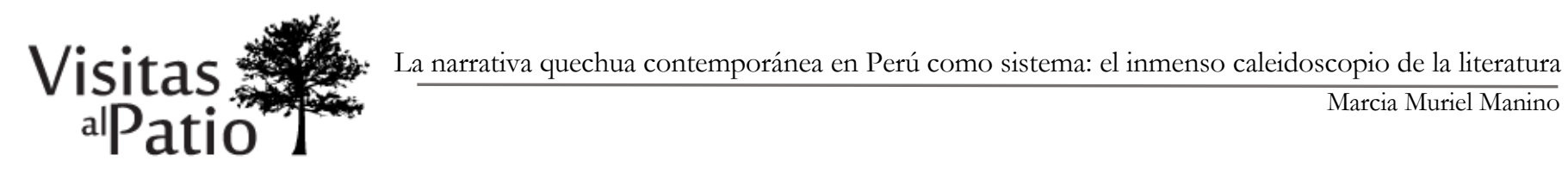

Iván (2004) y Los Rubios (2003), Garibotto expone su idea en torno a los documentales producidos después del año 2000 por la segunda generación. Para ella, estos develan el incremento de la hegemonización del testimonio en Argentina exponiendo el agotamiento de las teorías subalternas y de trauma. En el cuarto capítulo expone cómo la narrativa testimonial no es ya una narración subalterna de la historia, sino que se ha convertido ahora en una versión hegemónica, con el estudio las películas Cautiva, Salamdra, Andrés no quiere dormir la siesta, El premio e Infancia clandestina; a las que llama "iconic films" (25). En su opinión, estas películas son un ejemplo convincente del rol hegemónico que cumple el cine testimonial durante el kirchnerismo.

En la conclusión Garibotto comienza con la anécdota de la entrevista que dio Mauricio Macri en agosto del 2016 a una periodista de BuzzFeed, para resaltar como las palabras del entonces presidente revelan el cambio de la narrativa acerca de la última dictadura, de contrahegemónica a hegemónica; y que ella utiliza como uno de sus argumentos centrales en el libro. Por otro lado, enfatiza que este cambio explica la fatiga hacia el uso del testimonio que se observa a partir del año 2000. No obstante, Garibotto se asegura en resaltar que sus observaciones no persiguen la intención de quitar relevancia a la narrativa testimonial. No es su intención criticar el género testimonial, sino que persigue una lectura de estos que incluya la centralidad en su historicidad. Rethinking Testimonial Cinema in Postdictatorship Argentina. Beyond Memory Fatigue no solo compele al lector a reflexionar sobre la extensa producción cinematográfica testimonial en relación al traumático pasado argentino, sino que también lo fuerza a considerar diversas opiniones académicas en el contexto de la evolución del estudio de este material en las últimas cuatro décadas. Este libro aporta un inteligente razonamiento sobre la fatiga existente con relación a las narrativas testimoniales, en el contexto particular de Argentina a partir del año 2003, trazando un itinerario político e histórico concreto de la trayectoria ideológica, de contrahegemónica a hegemónica. Sin duda, este libro se convertirá en una obligada lectura en relación a la narrativa testimonial argentina sobre la dictadura, ya que los aportes de Garibotto redefinen la obsoleta mirada hacia esta, y la transforman con una original e inteligente propuesta.

Preparado para la revista académica Visitas al Patio, María Soledad Paz-Mackay, St. Francis Xavier University (marzo 2020). 